\title{
ESIS ions injection, holding and extraction control system
}

\author{
E.D. Donets, E.E. Donets, D.E. Donets, D.A. Lyuosev, D.O. Ponkin, A.Yu. Ramsdorf, \\ A.Yu. Boytsov, V.V. Salnikov, I.V. Shirikov ${ }^{1}$ \\ ${ }^{1}$ Laboratory of High Energy Physics, Joint Institute for Nuclear Research, 6 Joliot-Curie, Dubna, \\ Moscow region, 141980, Russia
}

\begin{abstract}
Electron string ion source (ESIS) KRION-6T is one of the main parts of the NICA injection complex [1]. During the work on creation of a new ion source for the NICA/MPD project the new ion motion control system was developed, produced and successfully put into operation. Modules development process and operation results are described.
\end{abstract}

\section{Introduction}

The Electron String type of Ion Sources (ESIS), was developed, constructed and tested firstly in the Joint Institute for Nuclear Research [2]. ESIS KRION-6T is currently designed at LHEP JINR in order to produce heavy ions [3]. KRION-6T operation is based on step-by-step ionization of the ions by hitting with electrons of an electron string and the main task is to produce the $\mathrm{Au}^{32+}$ ions for the NICA/MPD project. During the preparation of physics experiments with the ion source KRION$6 \mathrm{~T}$, it is necessary to apply special potential distribution for particle ionization and complex signal for beam extraction (Figure 1).

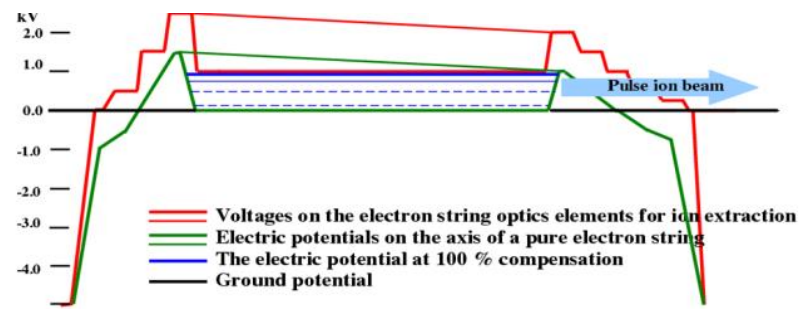

Figure 1. KRION-6T drift structure potentials

\section{General description}

Ions injection, holding and extraction control system contains several types of modules connected via RS-485 Modbus interface. The system is controlled from PC using Ethernet/optics and optics/RS-485 converters (Figure 2). Each module has its own Modbus ID. 


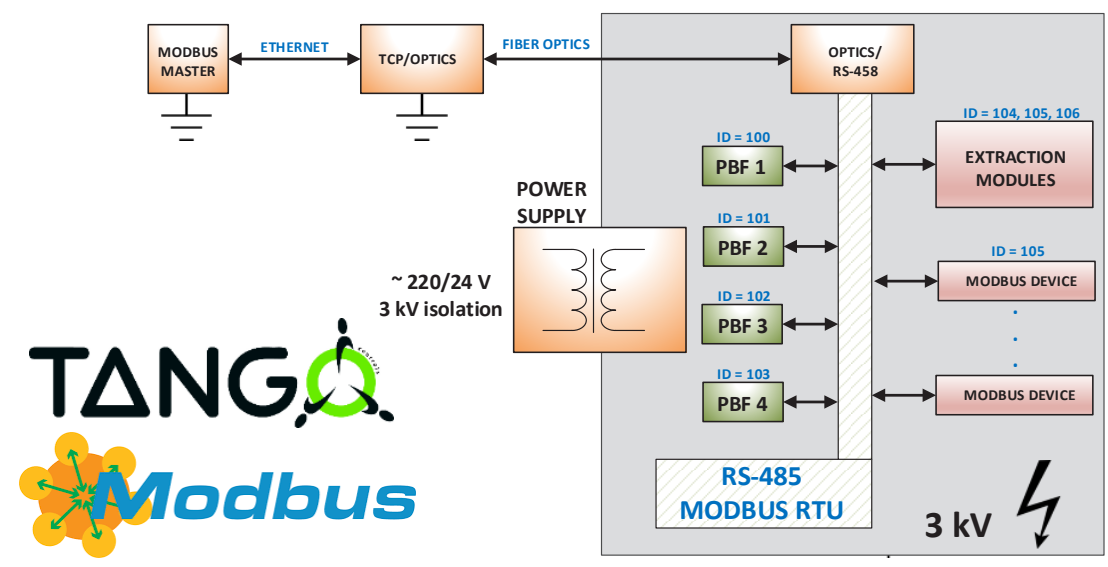

Figure 2. Functional diagram of the system

To complete ions holding task, potential barrier formation modules series (PBF) and DC high-voltage (HV) (HVFM 10.30) modules have been designed, produced and tested. The systems power supply module was also designed. To complete ions extraction task, extraction modules series were designed, produced and tested. In addition, several secondary devices were designed, produced and tested, as well.

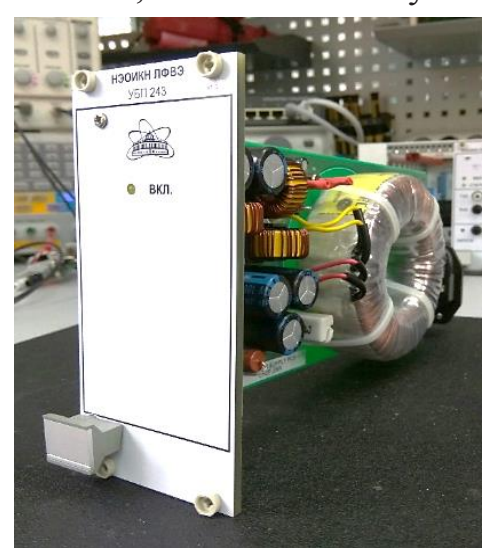

Figure 3. Power supply module

The special 24V 3A DC supply module with 4 $\mathrm{kV}$ electrical insulation supplies the system (Figure 3). Electrical insulation is necessary to provide the floating ground of the whole system, which is required for initial ion beam energy. The specifications:

- Supply: AC $220 \mathrm{~V}$;

- Output: DC 5 - 24V, up to $3 \mathrm{~A}$;

- Electrical insulation: $3 \mathrm{kV}$;

- Output protection: short circuit, overvoltage, overcurrent.

The module is based on a PWM switching controller TL494. All the injection, holding and extraction control systems modules are connected

to a single network using flat cable with common $+24 \mathrm{~V}$ line from this power supply unit. Total current consumption is about $1.8 \mathrm{~A}$.

The potential barriers formation modules (PBF) are pulsed HV modules with fiber optics trigger input (figure 4). The main idea of the module is based on a PWM switching controller, which supplies HV power transformer and HV IGBT transistors. Pulsed HV signal appear on the output at the time of the input trigger signal is applied. Thus, input trigger signal opens transistor, which is connected into the output circuit in a key mode. 32-bit ARM MCU performs output voltage and load current measurements, implements Modbus interface and PID-regulator logic. It 
allows controlling output voltage magnitude from PC using 12-bit DAC in the same way as using front panel variable resistor. To improve output signal linearity the MCU DAC based PID-regulator was implemented. The PBF modules specifications:

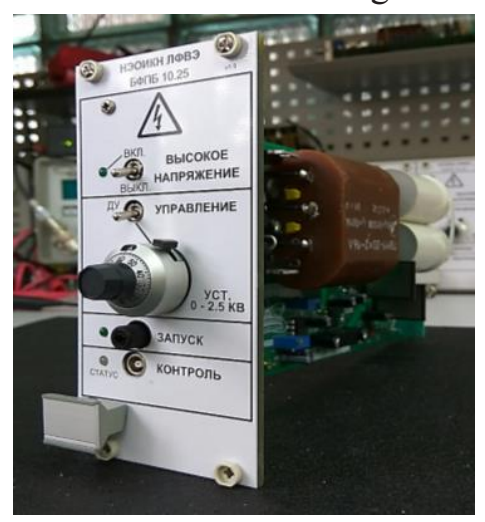

Figure 4. PBF 10.25 module
- Output: $\quad 0 \ldots+3 \mathrm{kV}$;

- Rise time: $\quad \sim 10$ us;

- Pulses width: $\quad 50$ us $-10 \mathrm{~s}$;

- Max load current: $8 \mathrm{~mA}$;

- Supply: $\quad+24 \mathrm{~V}, 300 \mathrm{~mA}$;

- Overcurrent, short circuit protection;

- Modbus interface;

- Manual \& Remote control.

Figure 5 shows $+3 \mathrm{kV} 1 \mathrm{~s}$ pulse output signals difference in cases of manual mode control using front panel variable resistor and MCU-based control with PID-regulator.
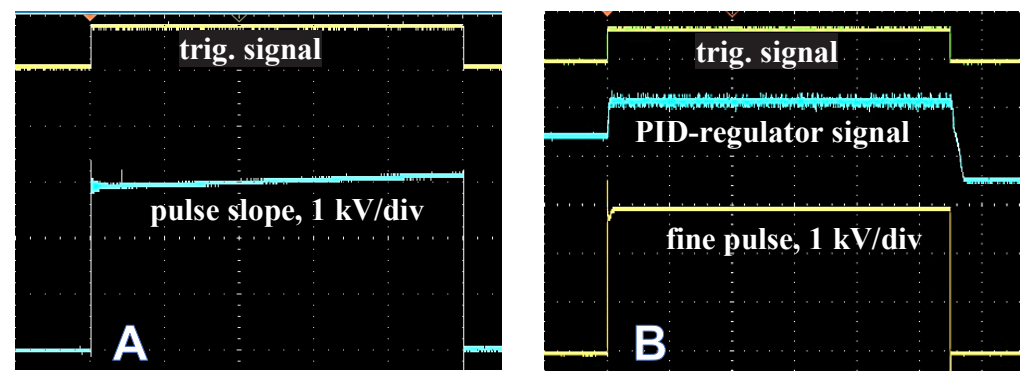

Figure 5. PBF 10.25 module output signal for two cases: A) manual mode control, B) remote control

The DC HV (HVFM 10.30) modules are another ions injection, holding and extraction control systems elements, which creates static potential barriers, positive potential biases and produce HV for modulator of the beam extraction system. The HVFM 10.30 modules working principle is also based on a PWM switching controller, which supplies HV power transformer. MCU logic is the same as in PBF 10.25 module described above with the only difference lying in input trigger signal absence necessity. The HVFM 10.30 modules specifications:

- Output: $\quad 0 \ldots+3 \mathrm{kV}$;

- Max load current: $10 \mathrm{~mA}$;

- Supply: $\quad+24 \mathrm{~V}, 300 \mathrm{~mA}$;

- Overcurrent, short circuit protection;

- Modbus interface;

- Manual \& Remote control.

The HVFM 10.30 modules have the same as the PBF 10.25 PC program GUI functionality. User can remotely control the output state, magnitude level and analyze status and measurements. 
However, from the point of view of the team of authors, the most interesting devices are beam extraction modules, which consist of the DC HV source (HVFM 10.30), HV modulator (Figure 6) and capacitive storage device. To extract the ion beam it is necessary to create a special pulse of complex shape in case of slow extraction (100 - 300 us width) and fast rising edge pulse for quick extraction case ( $1-10$ us width). This pulsed potential is applied to one of the beam drift structure parts simultaneously with of extraction process.
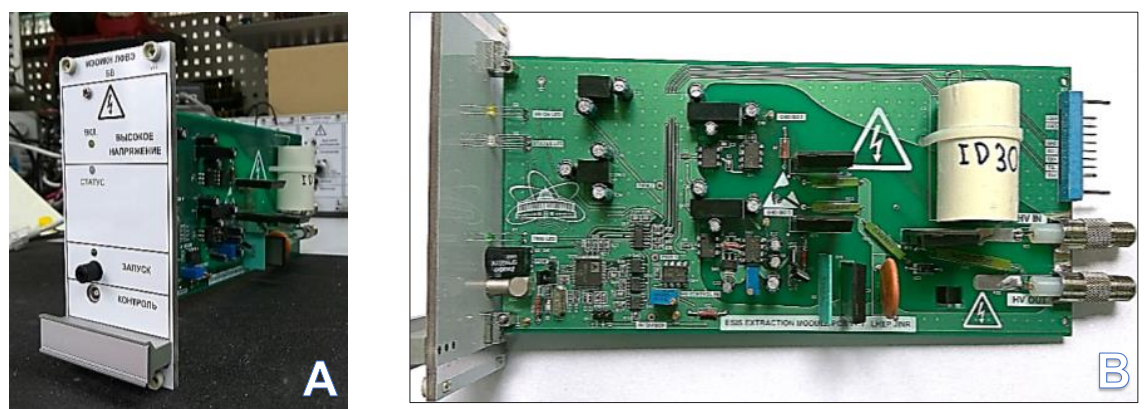

Figure 6. ESIS extraction system HV modulator: A) front panel, B) PCB view

Thus, the HV modulator is a special device, which allows user to create external triggered complex shape or fast rising edge HV pulse. External trigger is based on the fiber optics to TTL converter circuit. Fiber optics is used due to the systems floating ground. The main idea of the HV modulator is PWM-based HV IGBT transistors control. In this case, the transistor output is connected to the capacitive load and the HV modulator output is connected to the point of their connection.

To achieve a special slope of the pulse rising edge the different duty cycle PWM sections are applied. As well as duty cycle, user can also specify PWM section width. Thus, user can implement up to four time slots with different PWM duty cycle. Obviously, the higher PWM signal duty cycle is the faster is pulse rising edge. This is how pulse complex shape is achieved. Figure $6 \mathrm{~B}$ shows the HV modulators PCB a where couple of HV-connectors is shown. The top connector is DC HV input, the bottom one is modulated signal output. Figure 7 shows two pulses for different beam extraction cases which have been created using the HVFM 10.30, HV modulator and capacitive storage modules (beam extraction system).
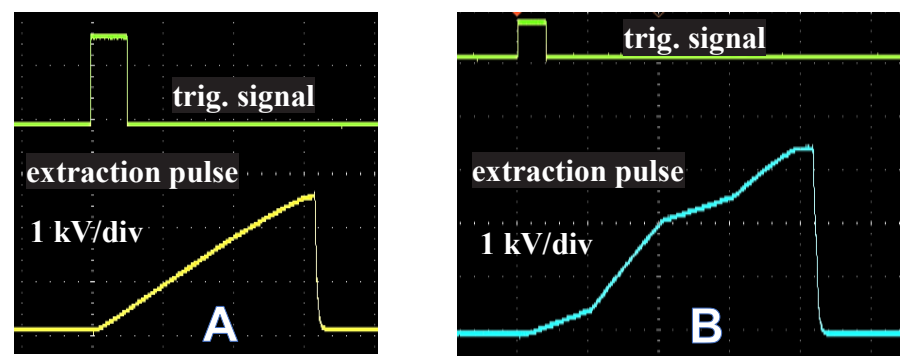

Figure 7. Beam slow extraction pulse for two cases: A) common, B) complex shape 


\section{Conclusion}

The new ions injection, holding and extraction control was successfully put into operation (Figure 8). The basic stand-alone PC software was also designed to control and monitor beam motion processes. The software was modified according to requests from users after first test run and currently works without any errors and bugs. It is based on the Visual C\# WPF technology where Modbus RTU over TCP transport class is designed by the authors. The choice in favor of Visual C\# WPF instead of TANGO controls [4] was made based on the real-time HV monitoring requirements. The next step is to connect the system with ESIS TANGO controls database on the monitoring level. The group of authors is also going to design similar $\mathrm{HV}$ devices with the maximum output voltage up to $\pm 12 \mathrm{kV}$.
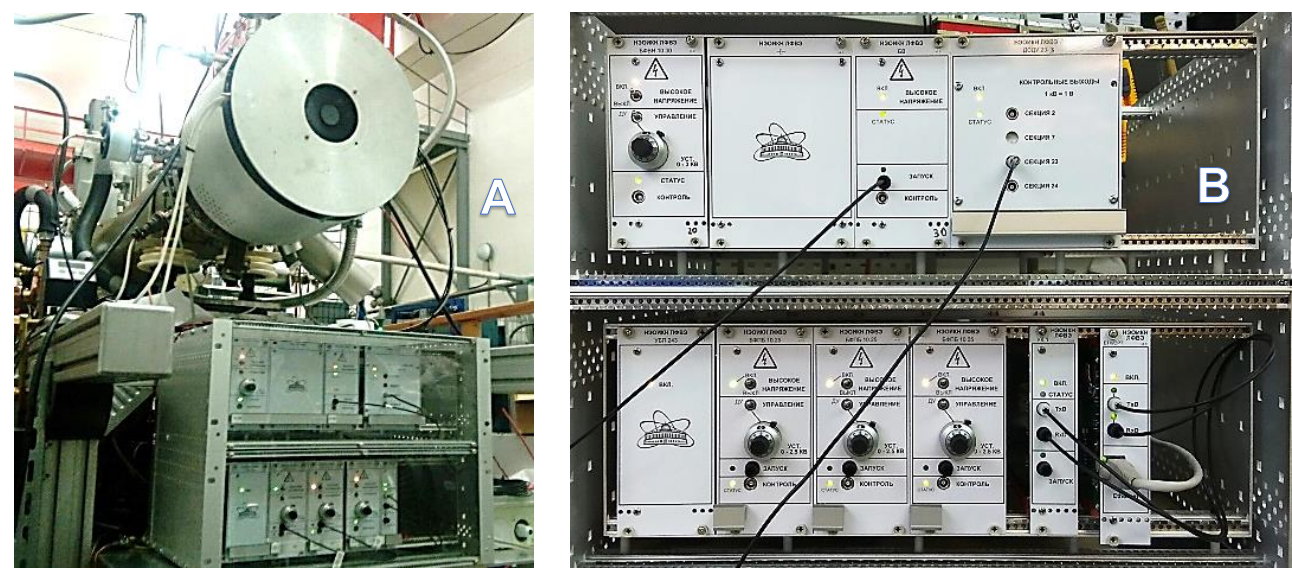

Figure 8. ESIS ions motion control system: A) during KRION-6T work, B) at the test bench

\section{References}

\section{NICA (Nuclotron-based Ion Collider fAcility). http://nica.jinr.ru/}

2. E.D. Donets, D.E. Donets, E.E. Donets, V.V. Salnikov, V.B. Shutov, S.V. Gudkov, Yu.A. Tumanova and V.P. Vadeev, Rev. Sci. Instrum., Vol. 75, 1543-1545 (2004).

3. D.E. Donets, E.E. Donets, T. Honma, K. Noda, A.Yu. Ramsdorf, V.V. Salnikov, V.B. Shutov and E.D. Donets, «Physics research and technology development of electron string ion sources», Rev. Sci. Instrum. 83, 02A512 (2012).

4. V. A. Andreev, V. I. Volkov, E. V. Gorbachev, V. A. Isadov, A. E. Kirichenko, S. V. Romanov, and G. S. Sedykh, TANGO Standard Software to Control the Nuclotron Beam Slow Extraction, Physics of particles and nuclei letters vol. 13 no. 5 pp. 951-956, (2016). 